\title{
Construction of the Comprehensive Training Mode of Clinical Talents
}

\author{
Na Wang \\ Department of Anesthesiology \\ The First Hospital of Jilin University \\ Changchun, China \\ wangna080613@163.com
}

\author{
Corresponding author: Jinguo Wang \\ Department of Urology \\ The First Hospital of Jilin University \\ Changchun, China \\ wangjinguolily@163.com
}

\begin{abstract}
On the base of the demand for modern medicine, the education idea, the curriculum reform and the way of quality control, teaching reform and teaching innovation, the construction of community medical practice base and so on to measure clinical medical talent training mode in an all-round way. Clinical medicine should be adhering to the advantages of running and make comprehensive medical university, based on the discipline construction, faculty construction, with emphasis on the reform of medical education, based on the modern medical demand goal, constructs the comprehensive training mode of talents.
\end{abstract}

Keywords-construction; training mode; clinical; comprehensive talents

\section{INTRODUCTION}

Clinical medicine is the basis of medical education and is the most essential way to train medical professionals. Due to the deluge of utilitarianism, the loss of humanistic spirit in the medical community creates some medical personnel's behavior anomie. This may cause the doctor-patient relationship tense and low social moral evaluation to the medical workers [1]. It has a harmful effect on the professional spirit of medical students. As the change of environment health reform in recent years, the enrollment expansion of colleges and universities, the competition between hospitals increased, the consciousness of patients has been increasing, there are increasing contradictions between the shortage of clinical teaching resources, clinical training quantity and quality of medical students increasingly landslide [2].

\section{The Evaluation System IS NOt ReAsonable}

\section{A. Unreasonable Examination Mode}

At present, the unreasonable examination mode is still play a leading role, especially the disposable end phase of the request for testing is still dominant in the college exam. This way of monotonous examination makes exams to become a burden and a short-term behavior. The problem of teaching and learning cannot be accurately diagnosed. We will not achieve the goal of developing the students' knowledge, ability and quality [3].

The test content is limited to the basic knowledge and skills in the teaching materials, and lacks the comprehensive examination of the students' knowledge, ability and quality.
Memory components make up too much. Moreover, the test problem is not reasonable, and the proportion of the objective test is large [4]. The comprehensive thought problem and the analysis are the short, which makes the examination a kind of encouragement to the memorization. It is not conducive to the cultivation and innovation of students' thinking, analysis, and comprehensive ability.

\section{B. The Study Process should be focused}

Such traditional assessments often require students to focus on the results. But they are indifferent to how students get these results. Formative evaluation is a kind of evaluation that pays attention to the process [5]. Only in the course of teaching can we understand the students' problems, efforts and progress. It is possible for the sustainable development of students and improve the effective guidance: because of focus on process, it can effectively help the students form active study attitude and scientific exploring spirit, to pay attention to students' emotional experiences in the learning process and realize the knowledge and skills, process and methods of comprehensive development [6].

It is common that clinical medical education curriculum aging, old content, weak practical courses of humanities and social science and medicine and ignorance of the cultivation of students' self-study ability, create a difference in the pressure of the medical students' practical ability, the knowledge structure is unreasonable, the lack of creative thinking, lack of selflearning and lifelong learning ability, social adaptability were some problems [7]. Practice opportunities for medical students are low, and theory is out of touch with practice training. The intern's medical practice power lacks special legal limits, making its clinical practice more narrow. Medical students lack basic scientific thinking training, scientific research consciousness and lack of ability [8].

\section{The BASIC PRINCIPLE OF CUlTuRE OF THE COMPREHENSIVE CLINICAL TALENTS}

Comprehensive training mode refers to the current medical education requires students not only have solid professional foundation, also to student's humanities concern, ethical and moral standards have quite high demand, namely to avoid the evils [9]. Comprehensive refers to from multiple links, and comparison, choose, take a variety of best ways and means, to achieve such a final goal to cultivate inter-disciplinary talent. 
This pattern requires the integration of education and the humanistic quality education [10].

\section{A. International Principles}

We will increase the strength of bilingual teaching and use the education resources of foreign excellent general medical science, and gradually implement the integration of the international standard [11]. To adapt to the community health service requirements, to the urgent need of medical talents oriented, speed up the medical professionals to solve actual problem ability and the cultivation of community health service ability. Following the idea of the education, we should expand the proportion of practice teaching and strengthen the theoretical knowledge in clinical practice. Build in medical ethics culture as the spirit connotation of university campus culture, to develop the medical simulation education, to strengthen the teaching of humanities and social medicine, development to learn the humanities spirit and professional big bosom, to ease the shortage of medical education resources, building a harmonious legal compatible clinical environment is of great significance [12].

\section{B. Applicability Principle}

Both of the development of science and technology into the information age, differentiation, and highly integrated, and comprehensive trend is obvious, science and technology into productivity speed, short cycle, humanities and science and management science to promote all-round development of economy and society, promote the role of nature of science and technology development is more and more big [13]. The scientific and technical characteristics of this background are: master the latest technology and the ability to acquire new knowledge. The basic knowledge is solid and broad, with the combination of the professional and the ability to use it strongly; Strong research, innovation and competitive ability; To have certain scientific knowledge of the humanities and social sciences; He is good at dealing with personal and social, scientific and economic relations, adapting to the rapid changes of society and self-adjusting ability [14].

\section{Practice Principle}

Medical model has been transformed from biomedical model to comprehensive medical model, as the core of the fiveyear medical talent training of clinical medicine professional education also should shift from "clinical type" to "compound", from "elite" to "families, practical", namely the theory of solid and superior skills, the humanities spirit, innovation ability and scientific research ability and community comprehensive service ability of high quality medical talents [15].

\section{Ethical Principles}

Consumers when deciding health services will have more say, also can ask the public health service providers by changing behavior and way of life, to protect and promote their health more responsibility. Because of the high price of new methods, new technology application in the medical practice, health administrative departments will be a series of rules and regulations to limit health fee hikes; various interventions in the health service cost effect analysis will become a regular work, lead to rising medical costs will be under supervision and control of behavior. Prevention will be more important to identify the health effects of socio-economic factors on the health of the population and identify the risk factors. The combination of public health and clinical practice will reduce health care costs and improve service efficiency.

\section{The TARget of CUlture OF THE COMPREHENSIVE CLINICAL TALENTS}

For a long time, we are very attention to the cultivation of medical core knowledge, with the development of information technology, it is easy to learn a new knowledge from the Internet, to cultivate the doctor the ability is more important to solve the problem. Future doctors should have the following abilities [16]. As a doctor, it is important to know how to communicate with the patient and learn how to communicate.

We should focus on the general rule of medicine and devote more time to mastering the basic laws of disease development. Future in front of the doctor can't just treat patients disease, but also attaches great importance to the patient's social environment, psychological and economic environment, considering the patient's quality of life after treatment and return to society. In the face of the current situation of medical problems and the social reality of the disease, the medical staff should not just complain about the unreasonable attitude of the patient. To focus on how the future doctors of education treat patients, understand the ethical consequences of the disease, and understand the impact of the physician's emotions on treatment [17].

\section{A. Communication Skills}

Providing effective health services to the overall needs of the patient for prevention, treatment and rehabilitation; consider the rational use of various diagnostic techniques from the aspects of ethics, patient expense, patient needs and ultimate interests; actively and effectively enhance the awareness of the health protection of individuals and groups, and promote the formation of a healthy lifestyle. Coordinate the needs of health care for individuals and societies to balance patient expectations with long-term, short-term expectations of the whole society; in a team approach, effective collaboration between the health sector, the health sector, and other social institutions [18]. In order for the new doctors to implement the above standards, the medical talents should have the following qualities: they have high personality and good demeanor, and they are highly responsible to others. A three-dimensional learning structure with medical, human and social sciences; Actively obtain, master and apply new knowledge and technology independently.

\section{B. The Ability to Apply Basic Science to Medical Practice}

More attention will be paid to the quality of health care, namely higher levels of satisfaction. The cost effectiveness and satisfaction of health services will be taken more seriously. Provide comprehensive, continuous and efficient services. The widespread use of information technology helps to establish information networks and participate in health decision-making processes among people of all kinds. Health workers will have the opportunity to work as a team and form a health service network with other departments [19]. 


\section{Adapted to the Community and the Environment}

Ability to engage in social work, including interpersonal communication, coordination and teamwork; Good physical and mental quality. A lack of historical knowledge, lack of artistic accomplishment, poor language skills, not evidencebased medicine doctor, how can from the heart of pain patients affinity and touching feelings, deep communication with therapy and psychological mood of patients for effective adjustment [20].

\section{The Ability to Combine Professional Skills with Humanistic Ideas}

Pay attention to humanistic education in medical education, create a new doctor of a high quality the humanities education, often referred to as social science and its related accomplishment and ability of knowledge, it is a new biological, psychological and social formation, and establish the foundation of the medical model. Medical research and service object is a person, assuming the sacred mission of protecting and promoting human health, medicine is supposed to be a most rich humanities and the science of human warmth. Professional lofty determines a full human person, otherwise, respect people, understand people, comfort, and love, will be due to the lack to talk.

\section{CONCLUSION}

New characteristics on the development of science and technology call for personnel training, the establishment of the modern biological, psychological and social medical model, the requirements of medical education should follow the medicine pattern organization teaching, curriculum setting and training future doctors; Social development and progress of science and technology, the characteristics of health service development, and a future doctor should have the ability to bring new tasks and medical education connotation, puts forward higher requirements on higher medical education; The humanities and social attributes of medical science and the experience of foreign countries suggest that strengthening the humanities education in medical science education is not too slow.

\section{REFERENCES}

[1] Leeder SR, Sackett DL. The medical undergraduate programme at McMaster University: learning epidemiology and biostatistics in an integrated curriculum. Medical Journal of Australia. 1976.

[2] Astin J, Jenkins T, Moore L. Medical students' perspective on the teaching of medical statistics in the undergraduate medical cur-riculum. Statistics in Medicine. 2002.

[3] Boninger M. Scholarly Concentrations in the Medical Student Curriculum. Academic Medicine. 2010.

[4] Calman KC. Medical Education: Past, Present and future. Journal of Women s Health. 2006.

[5] Dawson C. Practical Research Methods: A user-friendly guide to mastering research techniques and projects. How to Books. 2002.

[6] BLAND J M. Teaching statistics to medical students using ProblemBased Learning: the Australian experience. BMC Medical Education. 2004.

[7] Collins A, Brown J, Newman S. Congnitive apprenticeship: Teaching the crafts of reading, writing, and mathematics. American Educator. 1989.

[8] Cash J, Behrmann M. Effectiveness of Cognitive Apprenticeship Instructional Methods in College Automotive Technology Classrooms. Journal of Industrial Teacher Education. 1997.

[9] Collins A, John S, Holum A. Cognitive Apprenticeship: Making Thinking Visible. http://www.21leam.org/arch/articles/brown_seely.html/. 2010.

[10] Schlager M, Fusco J, Schank P. Evolution of an online education community of practice. 2002.

[11] Henderson M. Sustaining the professional development of teachers through a virtual learning environment: Promoting effective teaching with ICT. The ED-MEDIA, World Conference on Educational Multimedia, Hypermedia \& Telecommunications. 2004.

[12] Cooke M, Irby DM, Sullivan W, et al. American medical education 100 years after the Flexner report. The New England Journal of Medicine. 2006.

[13] Ann Brown. The Design of Hypermedia Tools for Learning: Fostering Conceptual Change and Transfer of Complex Scientific Knowledge. Journal of the Learning Sciences. 2000.

[14] ACGME, ABMS. Joint Initiative Attachment: Toolbox of Assessment Methods, Version 1. 2000.

[15] Collins A, Brown J, Holum A. Cognitive apprenticeship: Making thinking visible. American Educator. 1991.

[16] Green ML. Graduate medical education training in clinical epidemiology, critical appraisal and evidence-based medicine: a critical.

[17] Muller JH, Jain S, Loeser H, et al. Lessons learned about integrating a medical school curriculum: perceptions of students, faculty and curriculum leaders. Medical Education. 2008.

[18] Norman G.Problem-based learning makes a difference. But why? Canadian Medical Association Journal. 2008.

[19] Colllins A, John S, Holum A. Cognitive Apprenticeship: Making Thinking Visible. http://www.21leam.org/arch/articles/brown_seely.html/. 2010.

[20] Stuckey B. Making the Most of the Good Advice: Meta-analysis of Guidelines for Establishing an Internet-Mediated Community of Practice. http://www.bronwyn.ws/publications/papers/good_advice.pdf. 2009. 